\title{
Technical note: A mathematical function to predict daily milk yield of dairy cows in relation to the interval between milkings
}

\author{
M. Klopčič, ${ }^{* 1}$ W. J. Koops, † and A. Kuipersł \\ *Department of Animal Science, Biotechnical Faculty, University of Ljubljana, Groblje 3, 1230 Domžale, Slovenia \\ †Department of Animal Production Systems, Wageningen University, Zodiac, 6708 WD Wageningen, the Netherlands \\ ‡Expertise Centre for Farm Management and Knowledge Transfer, Wageningen University and Research Centre, PO Box 35 , \\ 6700 AA Wageningen, the Netherlands
}

\begin{abstract}
The milk production of a dairy cow is characterized by lactation production, which is calculated from daily milk yields (DMY) during lactation. The DMY is calculated from one or more milkings a day collected at the farm. Various milking systems are in use today, resulting in one or many recorded milk yields a day, from which different calculations are used to determine DMY. The primary objective of this study was to develop a mathematical function that described milk production of a dairy cow in relation to the interval between 2 milkings. The function was partly based on the biology of the milk production process. This function, called the $3 \mathrm{~K}$-function, was able to predict milk production over an interval of $12 \mathrm{~h}$, so DMY was twice this estimate. No external information is needed to incorporate this function in methods to predict DMY. Application of the function on data from different milking systems showed a good fit. This function could be a universal tool to predict DMY for a variety of milking systems, and it seems especially useful for data from robotic milking systems. Further study is needed to evaluate the function under a wide range of circumstances, and to see how it can be incorporated in existing milk recording systems. A secondary objective of using the $3 \mathrm{~K}$-function was to compare how much DMY based on different milking systems differed from that based on a twice-a-day milking. Differences were consistent with findings in the literature.
\end{abstract}

Key words: daily milk yield, milking interval, milking system, mathematical function

\section{Technical Note}

Knowing the daily milk production of dairy cows is necessary for animal management and selection in breeding programs. The measurement in use is daily

Received November 17, 2012.

Accepted May 21, 2013.

${ }^{1}$ Corresponding author: Marija.Klopcic@bf.uni-lj.si milk yield (DMY), which is defined by the International Committee for Animal Recording (ICAR, 2011) as "milk production over 24 hours." Milking twice a day is a common practice in many countries. In that case, DMY is the sum of the yields over 2 milkings.

Currently, however, milkings are not always twice a day, but range from once a day (Mackenzie et al., 1990) to twice, 3 times, or more with robotic milking (Bouloc et al., 2003). Official milk-recording data, therefore, originate from herds with different milking systems and milk-recording systems and, therefore from different numbers of milk recordings per day. For each milking system, a method has been developed (ICAR, 2011) to predict DMY. These methods use correction factors derived from large sets of milk-recording data. Estimation of breeding values, moreover, is based on DMY. For the purpose of estimating breeding values, ideally the same prediction method for all milking systems should be used. For instance, when the same cow is milked 3 or more times a day instead of twice a day, the DMY will be higher, in most cases resulting in overestimation of the breeding value (Miglior, 2004).

The primary aim of this study was to investigate the relationship between the milk produced by a cow and the milking interval (the time between 2 milkings). Because DMY is traditionally based on 2 milkings a day, 2 milkings is the standard in recording systems (ICAR, 2011). An important parameter to calculate, therefore, is the milk production over an interval of 12 h. A mathematical function was developed to predict milk production over an interval of $12 \mathrm{~h}$ (720 min). A secondary aim was to compare how much DMY based on different milking systems differs from DMY based on a twice-a-day milking system. The new mathematical function was used for those comparisons.

Many mathematical models (Everett and Wadell, 1969; Lee and Wardrop, 1984; DeLorenzo and Wiggans, 1986; Hargrove, 1994; Cassandro et al., 1995; Liu et al., 2000; Klopčič, 2004) have been proposed to predict DMY from 1 or 2 milkings a day. These models did not use information based on the biological relationship between milk production and the interval in which the 
Table 1. Milk and fat production for a cow with milking intervals of 1 through $36 \mathrm{~h}^{1}$

\begin{tabular}{|c|c|c|c|c|c|}
\hline \multicolumn{2}{|c|}{ Interval } & \multicolumn{2}{|c|}{ Milk } & \multicolumn{2}{|c|}{ Fat } \\
\hline h & $\min$ & lb. & $\mathrm{kg}$ & $\mathrm{g}$ & $\%$ \\
\hline 1 & 60 & 1.1 & 0.50 & 38 & 7.6 \\
\hline 2 & 120 & 1.7 & 0.77 & 60 & 7.8 \\
\hline 3 & 180 & 2.8 & 1.27 & 88 & 6.9 \\
\hline 4 & 240 & 3.2 & 1.45 & 91 & 6.3 \\
\hline 5 & 300 & 4.3 & 1.95 & 117 & 6.0 \\
\hline 6 & 360 & 4.3 & 1.95 & 115 & 5.9 \\
\hline 7 & 420 & 5.8 & 2.63 & 142 & 5.4 \\
\hline 8 & 480 & 6.5 & 2.95 & 153 & 5.2 \\
\hline 9 & 540 & 6.7 & 3.04 & 164 & 5.4 \\
\hline 10 & 600 & 8.2 & 3.72 & 179 & 4.8 \\
\hline 11 & 660 & 9.0 & 4.08 & 192 & 4.7 \\
\hline 12 & 720 & 9.6 & 4.35 & 196 & 4.5 \\
\hline 13 & 780 & 10.2 & 4.63 & 194 & 4.2 \\
\hline 14 & 840 & 9.6 & 4.35 & 170 & 3.9 \\
\hline 16 & 960 & 10.7 & 4.85 & 184 & 3.8 \\
\hline 18 & 1,080 & 11.7 & 5.31 & 223 & 4.2 \\
\hline 20 & 1,200 & 12.8 & 5.81 & 238 & 4.1 \\
\hline 24 & 1,440 & 13.3 & 6.03 & 278 & 4.6 \\
\hline 28 & 1,680 & 14.7 & 6.67 & 313 & 4.7 \\
\hline 32 & 1,920 & 15.4 & 6.99 & 251 & 3.6 \\
\hline 36 & 2,160 & 14.7 & 6.67 & 253 & 3.8 \\
\hline
\end{tabular}

${ }^{1}$ Derived by visual inspection from Figure 21.3 of Brody (1945). Fat grams were calculated from fat percentage and milk yield.

milk was produced. Neal and Thornley (1983) developed a dynamic simulation model for milk production in the mammary gland. The model was based on the number and activity of the secretory cells and the effects of hormones. Milk production, in relation to the interval between the current milking and the previous milking, showed an exponential increase at the beginning and later leveled off to an asymptote. This behavior was assumed to be the result of cell degradation and milk present in the udder. Brody (1945) showed milk yields and fat percentages for milking intervals between 1 and $36 \mathrm{~h}$; data for milk and fat production were derived by visual inspection from Figure 21.3 of Brody (1945) and are presented in Table 1.

To develop a mathematical model to describe the relation between milk production $\left(m_{t}\right)$ and preceding interval $(t), 3$ requirements were needed (Everett and Wadell, 1969; DeLorenzo and Wiggans, 1986; Liu et al., $2000)$ : the function must be asymptotic $\left(m_{t} \rightarrow m_{\infty}\right.$ as $t$ $\rightarrow \infty)$, it has to go through the origin $\left(m_{0}=0\right.$ if $\left.t=0\right)$, and it should have a minimum number of parameters.

Because milk production in the mammary gland is based on cell division, it must be considered a multiplicative process, and a logarithmic transformation should be used (Snedecor and Cochran, 1989): $\ln \left(m_{t}\right)$ or $\ln \left(m_{t}\right.$ +1 ), in which $m_{t}$ is the milk production in kilograms over an interval of $t$ minutes. The transformation of $\ln \left(m_{t}+1\right)$ was chosen because it is 0 at $t=0$ and the result is always a nonnegative value. The MichaelisMenten function (Brown and Rothery, 1993) meets the requirements mentioned above and is suitable for this purpose, so that

$$
\ln \left(m_{t}+1\right)=\ln \left(m_{\infty}+1\right)\left(\frac{t}{b+t}\right),
$$

where $m_{t}$ is the milk production $(\mathrm{kg})$ over an interval of $t$ (min), parameter $m_{\infty}$ is the asymptotic milk production of the cow $(\mathrm{kg})$ for $t=\infty$, and parameter $b$ (min) regulates the curvature. If $t=b$, then the value of $\ln \left(m_{b}\right.$ $+1)=0.5 \ln \left(m_{\infty}+1\right)$.

Equation [1] was fitted to the milk data of Brody (1945) in Table 1, by using nonlinear regression (NLREG version 5.3; Sherrod, 2002). Results are presented in Figure 1. The graph shows an almost perfect fit $\left(\mathrm{R}^{2}\right.$ $=0.99)$. The estimate of $m_{\infty}$ was $12.13 \mathrm{~kg}$ and that of $b$ was $391 \mathrm{~min}$.

To more easily interpret Equation [1], it was reorganized and reparameterized. Parameter $m_{720}$, which is the milk production over an interval of $720 \mathrm{~min}$, replaced $m_{\infty}$, and parameter $k$ replaced parameter $b$, where $k$ is the ratio $\ln \left(m_{720}+1\right) / \ln \left(m_{\infty}+1\right)$, a value between 0 and 1 . If $k=0$, the function is a straight line; if $k=1$, the function is a constant. The result of reparameterization was

$$
\ln \left(m_{t}+1\right)=\ln \left(m_{720}+1\right)\left(\frac{t}{720+k(t-720)}\right) .
$$

To work in the original $m_{t}$ scale, the function was back transformed to 


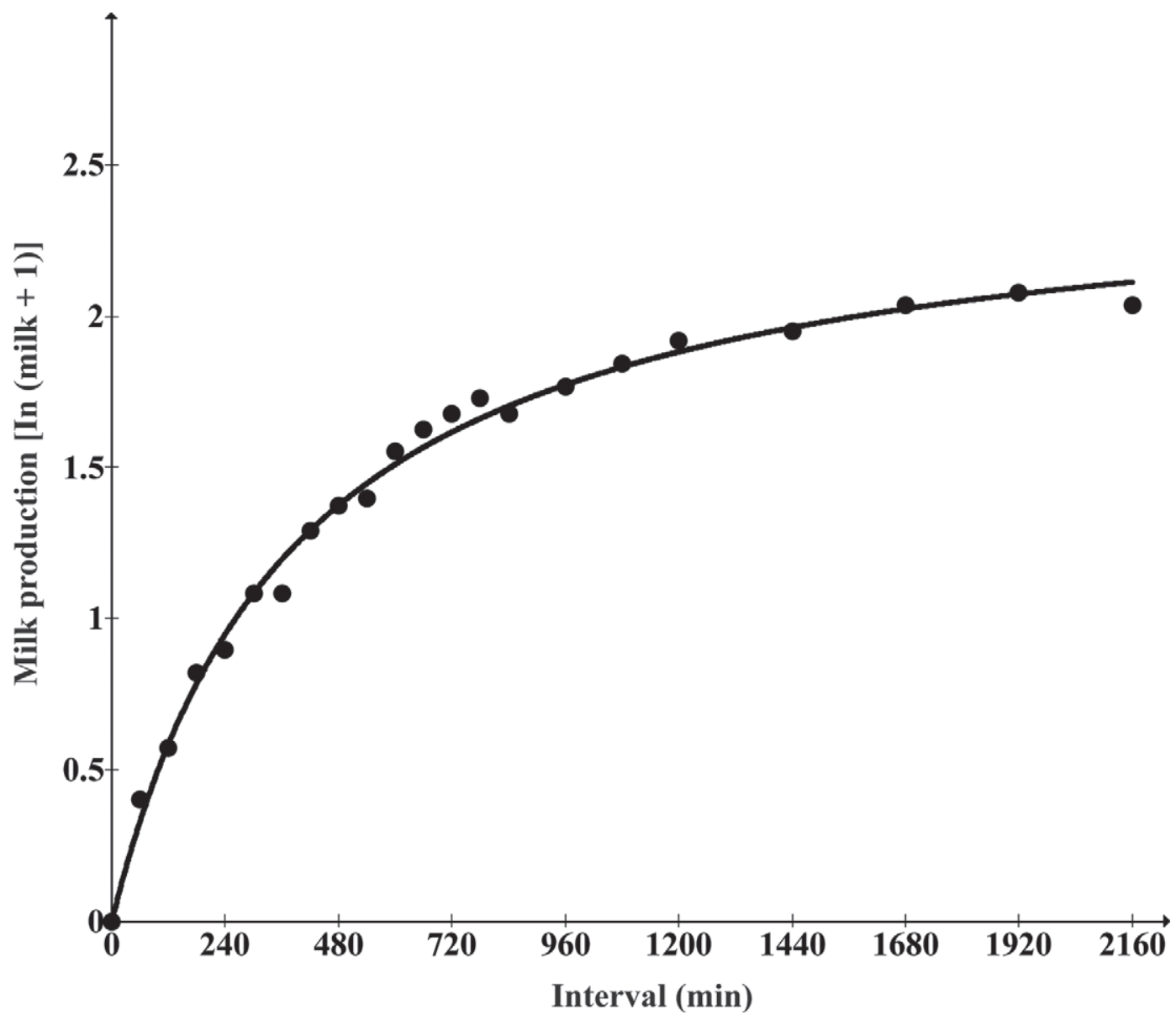

Figure 1. Relation between transformed milk production $\left[\ln \left(m_{t}+1\right)\right]$ and milking interval $(t)$ for the Brody cow (data from Table 1; Brody, 1945). The equation for the line is $\ln \left(m_{t}+1\right)=\ln (12.13+1)\left(\frac{t}{391+t}\right)$.

$$
m_{t}=\left(m_{720}+1\right)^{\left(\frac{t}{720+k(t-720)}\right)}-1 .
$$

Equation [3], hereafter the $\mathbf{3 K}$-function, is a nonlinear model that has to be solved using a nonlinear regression program. If such a program is not available, Equation [2] can be linearized by reorganizing the terms according to the method of Hanes and Woolf (Brown and Rothery, 1993). The simple linear regression equation becomes

$\frac{t}{720} \frac{1}{\ln \left(m_{t}+1\right)}=\frac{1}{\ln \left(m_{720}+1\right)}-k \frac{1}{\ln \left(m_{720}+1\right)}\left(1-\frac{t}{720}\right)$

of the form $y=a-b x$. The new variables are $y=\frac{t}{720} \frac{1}{\ln \left(m_{t}+1\right)}$ and $x=1-\frac{t}{720}$, and the new parameters are $a=\frac{1}{\ln \left(m_{720}+1\right)}$ and $b=\frac{k}{\ln \left(m_{720}+1\right)}$. Pa- rameter $m_{720}$ can be calculated as $\mathrm{e}^{(1 / a)}-1$, and $k$ is derived as a ratio: $k=b / a$.

Data used to test the validity of the $3 \mathrm{~K}$-function (Equation [3]) were from a Dutch farm with a robotic milking system (data set $\mathbf{R}$ ) and from 2 Slovenian farms with automatic recording systems (data sets 10/14 and 12/12) and milking intervals of $10 / 14 \mathrm{~h}$ and $12 / 12$ $\mathrm{h}$, respectively. In data set $\mathrm{R}$, milk yield for each milking and time of milking of the Holstein-Friesian cows or crossbreds of Holstein-Friesian were recorded. Milk yield was recorded twice a day with time of milking of HF cows. From each of the 3 data sets, 4 cows were randomly selected. Within each cow, 1 period of $28 \mathrm{~d}$ was randomly chosen. All recordings of $28 \mathrm{~d}$ were used in the statistical analysis. We assumed that differences between a.m. and p.m. milk yields were completely the result of differences in intervals, although we know the circadian system affects daily milk production (Harvatine, 2012; Plaut and Casey, 2012). These effects are assumed to be caused mostly by the diurnal rhythm and are expressed as differences between a.m. and p.m. 
yields. In Table 3 of DeLorenzo and Wiggans (1986), it was shown that, in a large data set, a.m. production contributed $50.5 \%$ to the DMY for intervals of 720 to 734 min. Equation [3] can be extended with a component $(u)$ such that the difference $(v)$ between a.m. and p.m. production can be estimated:

$$
m_{t}=\left[\left(m_{720}+v \cdot u\right)+1\right]^{\left(\frac{t}{720+k(t-720)}\right)}-1,
$$

where $u$ is a code for a.m. or p.m. milkings, and $u=$ $+1 / 2$ for a.m. milkings and $u=-1 / 2$ for p.m. milkings. The $m_{720}$ estimate based on a.m. and p.m. production, respectively, is $m_{720}+$ or $-v$. The difference of $m_{720}$ for a.m. and p.m. is $\left(m_{720}+1 / 2 v\right)-\left(m_{720}-1 / 2 v\right)=$ $v$. If DMY is predicted as $2 m_{720}$ or as the sum of a.m. and p.m. $m_{720}$ estimates, there is no difference because $\left(m_{720}+1 / 2 v\right)+\left(m_{720}-1 / 2 v\right)=2 m_{720}$. Ignoring the effect of $u$ means that variation caused by milking time will be part of the residual variation, which negatively affects the precision of the $m_{720}$ estimate. Equation [3a] holds for cases of a 12/12 h milking system and milking twice a day. With 3 or more milkings per day (such as in robotic milking), it is hard to distinguish between a.m. and p.m. milkings. To include all possible factors, creating a circadian or diurnal rhythm would result in a model with more parameters that is difficult to interpret. The effect of stage of lactation was considered to be small over a period of $4 \mathrm{wk}$ and, therefore, not accounted for in the model.

To test the $3 \mathrm{~K}$-function on data of the 12 randomly selected cows, the function was used on the original scale (Equation [3]). Equations [2], [3], and [4], however, gave similar estimates for $k$ and $m_{720}$. The original scale (Equation [3]) was chosen because the parameter values and graphs were on a familiar scale. The result for each cow is shown in Table 2. The fit for the cows of the $\mathrm{R}$ and $10 / 14$ groups was good, with $\mathrm{R}^{2}$ around 0.90 and a residual standard deviation around $1 \mathrm{~kg}$. Results for the 12/12 group, however, showed, as expected, small $\mathrm{R}^{2}$ values because there was almost no variation in intervals. Estimates for $k$, for cows of all groups, varied between 0.44 and 0.81 . Standard errors for parameter estimates were small, except for the 12/12 group, as expected.

The results of prediction are presented for 1 or 2 cows per data set in Figure 2. The cows were chosen so as to minimize overlap of results. Figure 2 shows that a 2-parameter function was able to fit milk yield of cows in each data set. At the same time, the function gives the estimate of $m_{720}$, which is the expected milk yield when a cow was milked at intervals of 720 min.

The use of the 3K-function is consistent with the statement of ICAR (2011) that the standard is 2 milk-

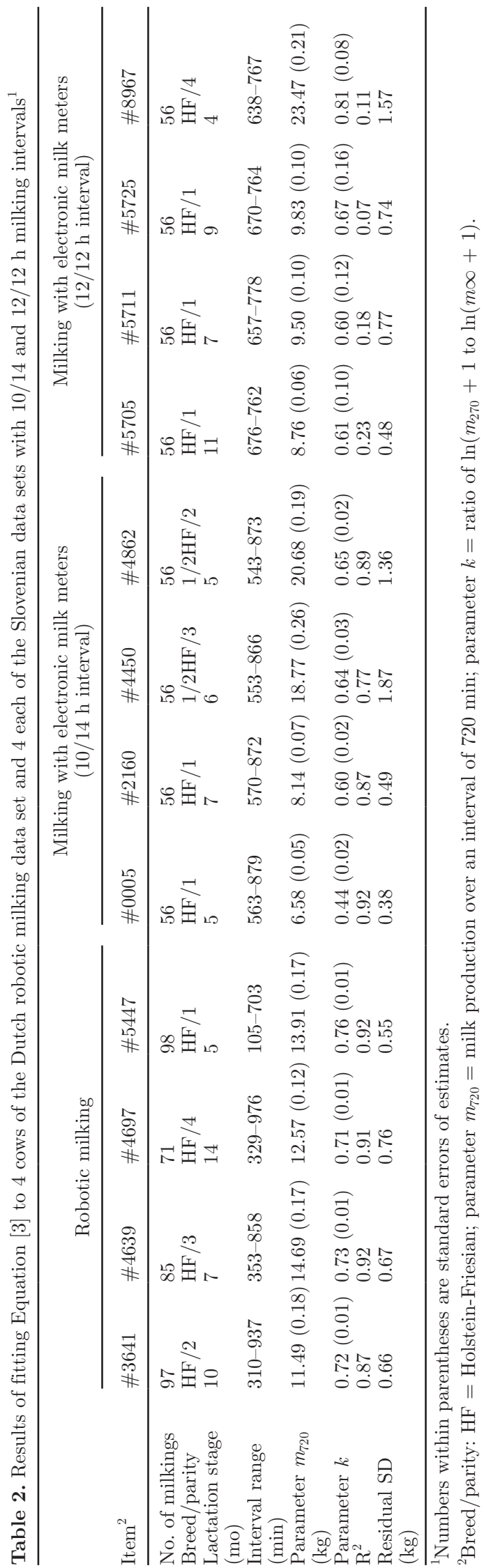

Journal of Dairy Science Vol. 96 No. 9, 2013 


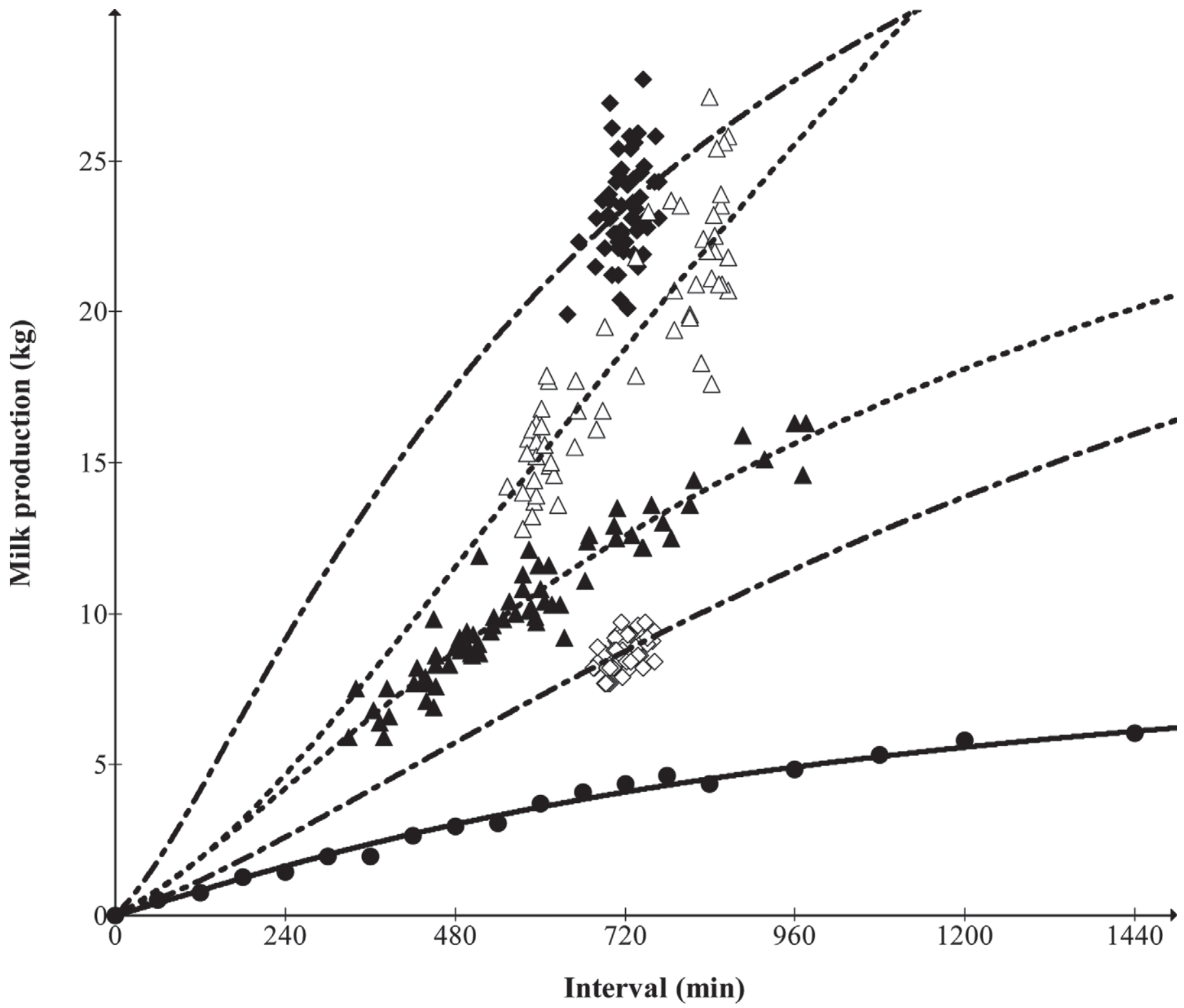

Figure 2. Typical patterns showing the relation between milk production and milking interval as a result of different milking systems: $=$ the "Brody" cow (Brody, 1945); $\diamond$ (cow 8967) and $\diamond($ cow 5705) $=$ cows milked with electronic milk meters with a $12 / 12 \mathrm{~h}$ interval; $\Delta$ (cow $4450)=$ cow milked with electronic milk meters with a 10/14 h interval; and $\boldsymbol{\Delta}$ (cow 4607) = cow in a robotic milking system with free access (see Table 2 for more information about these cows and parameter estimates using Equation [3]).

ings per day. Consequently, the definition of DMY is 2 times the 12-h milk production. To demonstrate the effect on DMY prediction when the presence of diurnal rhythm is also considered, Equation [3] was applied to cows of the 12/12 group (Table 2). The standard errors for the $m_{720}$ parameter for cows $5705,5711,5725$, and 8927 (Table 2) were, respectively, 0.06, 0.10, 0.10, and $0.21 \mathrm{~kg}$. When Equation [3a] was used, standard errors changed to $0.06,0.09,0.10$, and 0.20 , respectively. The inclusion of a third parameter in the 3K-function for the a.m.-p.m. difference had only a small effect on the precision of the $m_{720}$ estimate.
Because of the specific curvature of the $3-\mathrm{K}$ function, it was expected to be suitable for predicting milk content. To demonstrate this, Equation [3] was applied to fat production $\left(f_{t}\right)$ of the Brody cow in Table 1. Estimates were $190 \mathrm{~g}$ for $f_{720}$ and 0.72 for $k$, with an $\mathrm{R}^{2}$ of 0.95 .

The $3 \mathrm{~K}$-function also offers the opportunity to show how DMY changes when $n$ milkings per day $\left(\mathrm{DMY}_{n}\right)$ are recorded compared with 2 milkings per day $\left(\mathrm{DMY}_{2}\right)$. A simulation was made for cases of $n=1,2,3,4$, or 5 milkings per day. For each case, it was assumed that $n$ intervals of equal lengths exist. Then, $\mathrm{DMY}_{n}$ is the sum 
of the records over the $n$ intervals. Based on Equation (3), a function was derived where $\mathrm{DMY}_{n}$ is related to $\mathrm{DMY}_{2}$ :

$$
\mathrm{DMY}_{n}=n\left(\left(0.5 \mathrm{DMY}_{2}+1\right)^{\left(\frac{2}{n+k(2-n)}\right)}-1\right),
$$

where $\mathrm{DMY}_{2}$ is $2 \times m_{720}$ and $k$ is from the $3 \mathrm{~K}$-function. The number of milkings per day is $n$. Figure 3 shows the results of the simulation. The decrease in production for 1 milking per day was about $20 \%$ of $\mathrm{DMY}_{2}$, which is consistent with the findings of Mackenzie et al. (1990). For more than 2 milkings per day, we found an increase in production of about $10 \%$ of $\mathrm{DMY}_{2}$, which is consistent with findings of Smith et al. (2002) and Jacobs and Siegford (2012).
We conclude that the $3 \mathrm{~K}$-function developed here has the right characteristics to predict 12 -h milk production and therefore DMY, as was demonstrated with randomly selected cows from 3 different milking systems. The function is attractive because it has only 2 parameters and is easily extended with other factors such as a diurnal rhythm, as demonstrated with Equation [3a].The function may also have the potential to predict milk content, and it is able to measure the effect of $n$ milkings a day compared with 2 milkings a day. However, the behavior of the 3K-function should be evaluated in a large set of field data under a wide variety of circumstances, including different breeds, stages of lactation, and parities. Although Lee and Wardrop (1984), DeLorenzo and Wiggans (1986), and Gantner et al. (2009) included the effect of one or more of these factors in their studies, they found these factors not to be important sources of variation in the prediction

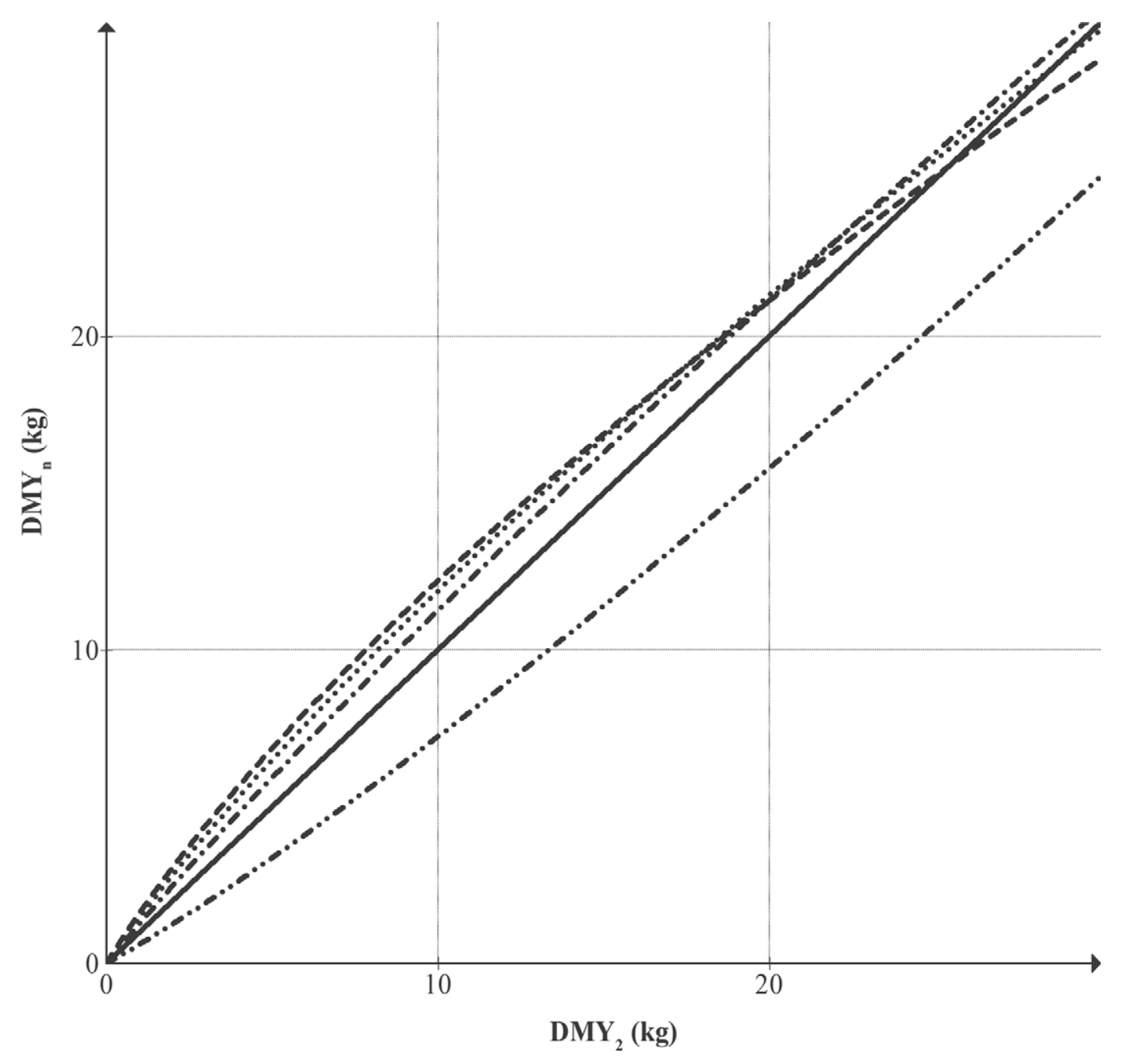

Figure 3. Effects of multiple milkings on daily milk yield (DMY) with a reference of 2 milkings per day $\left(D_{M M}\right)$. Number of milkings is $n$ with equal preceding intervals: $n=1 . . \cdot ; n=2-; n=3 .-\cdots-\cdots ; n=4 \cdots \cdots ; n=5----$. Parameter $k$ is fixed to 0.7 . 
of milk yield and content (although a herd effect may exist).

Furthermore, ways to incorporate this $3 \mathrm{~K}$-function in predictions of DMY and milk content for different milking and recording systems should be investigated and described. The 3K-function may be most useful to predict DMY for milking systems with several milkings a day.

\section{ACKNOWLEDGMENTS}

This study was part of Twinning project SI06/IB/ $\mathrm{AG} / 01 / \mathrm{TL}$ "Strengthening the implementation of Cross-Compliance and stimulating good farming practices" financed by the European Union and Slovenian Ministry of Agriculture. The authors thank Livestock Research WUR (Lelystad, the Netherlands) and the Slovenian farmers for providing the data. The authors also thank Michael Grossman (University of Illinois, Urbana) for correcting an earlier version of the manuscript. Comments of the anonymous JDS reviewers were greatly appreciated and led to some interesting additions to the manuscript.

\section{REFERENCES}

Bouloc, N., J. Delacroix, and V. Dervishi. 2003. Milk recording and automatic milking systems: Features and simplification possibilities of recording procedures. Page 57-64 in Proc. 33rd Bienn. Session of ICAR, Interlaken, Switzerland. Wageningen Academic Publishers, Wageningen, the Netherlands.

Brody, S. 1945. Bioenergetics and Growth. Reinhold Publishing Corporation, New York, NY.

Brown, D., and P. Rothery. 1993. Models in Biology. Mathematics, Statistics and Computing. John Wiley \& Sons Ltd., Chichester, UK.

Cassandro, M., P. Carnier, L. Gallo, R. Mantovani, B. Contiero, and G. Bittante. 1995. Bias and accuracy of single milking testing schemes to estimate daily and lactation milk yield. J. Dairy Sci. 78:2884-2893.

DeLorenzo, M. H., and G. R. Wiggans. 1986. Factors for estimating daily yield of milk, fat and protein from a single milking for herds milked twice a day. J. Dairy Sci. 69:2386-2394.
Everett, R. W., and L. H. Wadell. 1969. Relationship between milking intervals and individual milk weights. J. Dairy Sci. 53:548-553.

Gantner, V., S. Jovanovac, M. Klopcic, M. Cassandro, N. Raguz, and K. Kuterovac. 2009. Methods for estimation of daily and lactation milk yields from alternative milk recording scheme in Holstein and Simmental cattle breeds. Ital. J. Anim. Sci. 8:519-530.

Hargrove, G. L. 1994. Bias in composite milk samples with unequal milking intervals. J. Dairy Sci. 77:1917-1921.

Harvatine, K. J. 2012. Circadian patterns of feed intake and milk composition variability. Pages $43-55$ in Proc. Tri-State Dairy Nutrition Conference, Ft. Wayne, IN.

ICAR. 2011. International Agreement of Recording Practices. ICAR Guidelines. International Committee for Animal Recording (ICAR), Rome, Italy.

Jacobs, J. A., and J. M. Siegford. 2012. Invited review: The impact of automatic milking systems on dairy cow management, behavior, health, and welfare. J. Dairy Sci. 95:2227-2247.

Klopčič, M. 2004. Optimization of milk recording practices in dairy cows (Optimizacija vrednotenja proizvodnosti krav v mlečni usmeritvi). PhD Thesis. University of Ljubljana, Slovenia.

Lee, A. J., and J. Wardrop. 1984. Predicting daily milk yield, fat percent, and protein percent from morning or afternoon tests. J. Dairy Sci. 67:351-360.

Liu, Z., R. Reents, F. Reinhardt, and K. Kuwan. 2000. Approaches to estimating daily yield from single milk testing schemes and use of a.m.-p.m. records in test-day model genetic evaluation in dairy cattle. J. Dairy Sci. 83:2672-2682.

Mackenzie, D. D. S., G. A. Lynch, and M. E. Hunt. 1990. Once daily milking: Physiological responses, costs and benefits. Dairy Farming Annu. 42:79-84.

Miglior, F. 2004. Management of milk recording in herds with the automatic milking systems (AMS). Page 9-13 in Proc. 11th World Holstein Friesian Federation (WHFF) Meeting, Paris, France. WHFF, Brussels, Belgium.

Neal, H. D. St. C., and J. H. M. Thornley. 1983. The lactation curve in cattle: A mathematical model of the mammary gland. J. Agric. Sci. 101:389-400.

Plaut, K., and T. Casey. 2012. Does the circadian system regulate lactation? Animal 6:394-402.

Sherrod, P. H. 2002. Nonlinear regression analysis program, NLREG version 5.3. Philip H. Sherrod, Nashville, TN.

Smith, J. W., L. O. Ely, W. M. Grayes, and W. D. Gilson. 2002. Effect of milking frequency on DHI performance measures. J. Dairy Sci. 85:3526-3533.

Snedecor, G. W., and W. G. Cochran. 1989. Statistical Methods. 8th ed. Iowa State University Press, Ames. 